\title{
BIBLIOGRAFIA
}

\section{Una Bibliografía Descriptiva \\ "El Periquillo Sarniento" de José Joaquín Fernández de Lizardi}

Se ha recibido como una contribución importante la edición en inglés, debida a Katherine Anne Porter, de la novela mexicana más popular: El Periquillo Sarniento. El prefacio, que escribió, y la traducción, que revisó, prueban su competencia. E1 Itching Parrot ${ }^{1}$ al fin se exhibe atractivamente ante el público, con su plumaje bien pulido. Esta es una deuda quie esperamos será saldada por los lectores norteamericanos que no pudieron leer dicha obra en su lengua original. Sin embargo, después de hacer una presentación amena del pícaro perico, tanto la escritora como la casa editorial, tal vez con deseos de impresionar al lector, acuden a la fantasía para pintar al perico como pavo real. En el forro de la cubierta de esta edición afírmase que "se vendieron 100,000,000 de ejemplares". La señorita Porter añade, más modestamente: "Until the recent disaster in Spain, a big popular press in Barcelona reprinted it endlessly at the rate of more than a million copies a year." 2 Los críticos de dicha obra, así como los lectores, quedaron indebidamente impresionados con este best seller. Un examen cuidadoso de todas las ediciones conocidas del Periquillo, prueba què aquellas cifras eran muy exageradas.

De las veinte y cuatro ediciones registradas hasta el día, siete resultaron truncas, porque en la mayoría de los casos el público no compró bastantes ejemplares para sufragar los gastos de impren- 
ta. Al computarse las ediciones mexicanas, resulta que el promedio de ejemplares no pasó de-3,000. Un cálculo amplio del número total de ejemplares impresos en México ascendería aproximadamente a 25,000. La "imprenta popular de Barcelona" mencionada por la señorita Porter es la de Ramón Sopena. Este editor puso en circulación cuatro ediciones del Periquillo, una en 1901, otra en 1908," la tercera en 1933 y una cuarta más tarde. Comparando detenidamente tales ediciones, hallamos que las tres últimas se imprimieron con los mismos estereotipos empleados en la primera. La escritora trata de hacernos creer que un solo juego de clisés pudiera continuar imprimiendo la novela " ia razón de un millón de ejemplares cada año!" Unos 50,000 ejemplares sería el número total de aquellos producidos en España, los cuales, juntos con los de México, nos darían un total de 75,000. La diferencia entre esta cifra y la propuesta por el editor de $100,000,000$ de ejemplares, constituye un disparate digno del propio picaro Periquillo.

Quizás tales afirmaciones exageradas emanen de la falta de apropiada información acerca de las diversas ediciones. La bibliografía más reciente ${ }^{3}$ cuenta catorce impresiones, completas o truncas. En la que aquí se presenta catalogamos además otras diez, con una descripción completa de todas ellas. La ofrecemos como una rectificación a las aserciones erróneas hechas por la señorita Porter y otros escritores. ${ }^{4}$

El Periquillo es digno de su fama por la popularidad de que ya gozaba y no precisa atenerse a la exageración para ser excepcional, por haber sido escrita tal obra cuando todavía no se acostumbraba a escribir novelas y, sobre todo, por haber sido en el período colonial hispanoamericano la obra maestra de la literatura novelesca.

\section{Clave de las Bibliotecas}

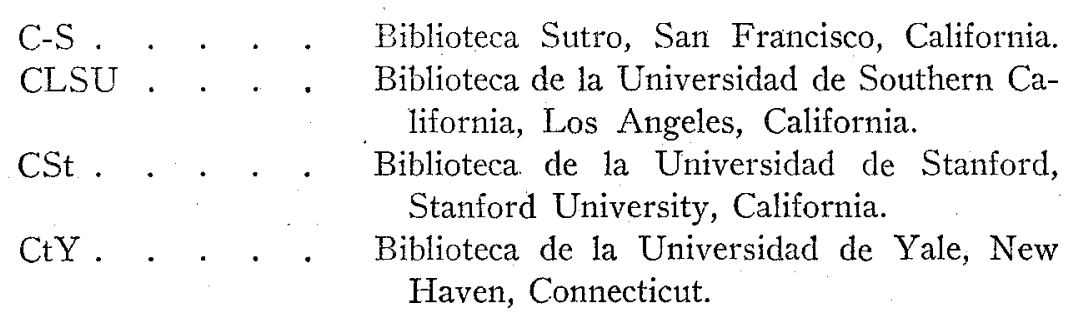


CU-B . . . . Biblioteca de Bancroft, Universidad de California, Berkeley, California.

DLC . . . Biblioteca del Congreso, Washington, D. C.

EM . . . . Biblioteca particular del autor, Nueva York.

IU . . . . Biblioteca de la Universidad de Illinois, Urbana, Illinois.

JRSI. . . . Biblioteca del doctor Jefferson R. Spell, Austin, Texas.

MdBJ . . . Biblioteca de la Universidad de Johns Hopkins, Baltimore, Maryland.

$\mathrm{MB}$. . . . . Biblioteca Pública de Boston, Boston, Massachusetts.

$\mathrm{MH}$. . . . Biblioteca de la Universidad de Harvard, Cambridge, Massachusetts.

MxCoah . . . Biblioteca del Ateneo Fuente, Saltillo, Coahuila, México.

$\mathrm{MxF}$. . . . Biblioteca Nacional, México, D. F.

MxFL . . . Biblioteca Lincoln, México, D. F.

MxFLGO . . Biblioteca particular de Luis González Obregón, México, D. F.

MxFPR . . Biblioteca particular de Pedro Robredo, México, D. F.

MxFU . . . Biblioteca de la Universidad, México, D. F. MxJ . . . Biblioteca Pública del Estado, Guadalajara, Jalisco, México.

$\mathrm{NcD}$. . . Biblioteca de la Universidad de Duke, Durham, North Carolina.

NN . . . . Biblioteca Pública de Nueva York, Nueva York, N. Y.

NNC . . . Biblioteca de la Universidad de Columbia, Nueva York, N. Y.

OO . . . Biblioteca de Oberlin College, Oberlin, Ohio. RPB . . . Biblioteca de la Universidad de Brown, Providence, Rhode Island.

TxU . . . Biblioteca de la Universidad de Texas, Austin, Texas.

ViU . . . Biblioteca de la Universidad de Virginia, University, Virginia. 


\section{EDICIONES}

1. E1 / Periquillo Sarniento. / Por el / Pensador Mexicano. / Tomo r. / Cori las licencias necesarias. / [raya] / México: / En la Oficina de D. Alexandro Valdés, calle / de Zuleta, año de 1816 . .

Tomo $1^{\circ}:$ p. [2] portada, v.: epígrafe de 5 líneas tomadas de la Barca de Aqueronte de Torres Villarroel; i-vii, "Prólogo, dedicatoria y advertencias a los lectores"; vii-x, "El prólogo de Periquillo Sarniento"; x-xiii, "Advertencias generales a los lectores"; xiii-xiv, "Advertencias a los señores subscritores"; 1-177, texto en 12 capitulos; [1] índice de capítulos; [2] lista de suscritores.

Tomo $2^{\circ}$ : p. [2] idem t. 1 pero "Tomo n"; i-iv, "Prólogo en trage de cuento"; 1-227, texto en 12 capítulos; [1] nota dirigida a los suscritores; [2] índice.

Tomo 3": p. [2] idem t. 1 pero "Tomo mi"; 1-228, texto en 12 capítulos; [2] índice.

$4^{\circ} 196 \times 143 \mathrm{~mm}, 12$ grabados en cada tomo por "Mendoza". Tanto las ilustraciones como la tipografía son de lo mejor de aquel entonces. La lista de suscritores contiene los nombres de 88 personas de la ciudad de México, 14 de las provincias. Entre los suscritores encontramos a cierto "D. Mariano Mendoza. Arquitec. y Académ. de la Rl. de S. Cárlos", que debe ser el Mendoza de las ilustraciones. Beristáin hace la primera referencia a esta novela en su Biblioteca bispano americana (véase la $2^{3}$ edición, Amecameca, 1883, t. 2, p. 169), dando a entender que leyó una parte del manuscrito. Lizardi compuso el Periquillo, según parece, en 1815. El prospecto de la novela salió a luz en diciembre de 1815 , como consta en la relación que hizo la Junta de Censores en aquel mes (Spell, p. 31). Existe un ejemplar del prospecto en la Biblioteca Sutro (C-S), que lo describe así: Prospecto / de la vida o aventuras / de Periquillo Sarniento. / Gratis a los Subscritores. /, sigue el texto y al fin: México, 1815. Imprenta de la calle de Santo Domingo y esquina Tacuba. 8 p., $20 \mathrm{~cm}$. Fué reproducido por Paul Radin en Some newly discovered poems and pamphlets of J.J. Fernandez de Lizardi, p. 59-65. En este escrito dice Lizardi que publicaría su obra en cuatro tomos, cada uno de 12 capítulos y con 12 grabados, a cuatro pesos el tomo. Agrega que daría a luz un capítulo el martes, otro el viernes, comenzando con la primera semana de febrero. Los periódicos del día y los informes de la 
Junta revelan también que 6 capítulos del tomo $1^{\circ}$ aparecieron durante febrero de 1816 ; que la publicación del tomo $2^{\circ}$ se anunció el 18 de abril; y que, antes de julio, 50 hojas del $3^{\circ}$ ya salieron. El tomo $4^{\circ}$ en manuscrito llegó a las manos del censor por intermedio del Virrey el 6 de octubre de 1816. El censor, Felipe Martínez, sugirió algunas enmiendas de poca importancia en su informe fechado a 19 de octubre del mismo año. El Virrey decretó el 29 de noviembre que "no siendo necesaria la impresión de este papel, archívese el original y hágase saber al autor, que no ha lugar á la impresión que solicita". Todos estos documentos se pueden consultar en las hojas preliminares del $4^{\circ}$ tomo, edición de 1842 . Tuvimos la suerte de descubrir que Lizardi no se contentó con la decisión del Virrey. Con la inventiva acostumbrada, hizo un resumen del último tomo $y$ empleó varios escribientes para hacer copias a mano. Evitó así la censura, que sólo podía suprimir los escritos impresos. Es de presumir que todos los suscritores que quisieran completar su colección de la novela compraron copias del extracto. De éste damos la descripción:

El / [raya doble] / Periquillo Sarniento / [raya doble] / Tomo N. / [raya] / Estractado [sic] Por el / [raya] / Pensador Mexicano. / [raya] / Año de 1817. / [raya doble] /

Portada, v. bl.; p. 1-43 texto sin dividirlo en capítulos; [1] bl.

No es la letra de Lizardi. Publicamos el texto de la copia que tenemos en el artículo "El compendio del tomo cuarto de El Periquillo Sarniento, manuscrito anotado y ensayo crítico", $A b$ side (México), t. III (1939), núm. 11 (noviembre), p. 1-13, y núm. 12 (diciembre), p. 1-30, que también estudia las variantes de la copia que posee el doctor Spell. El señor Felipe Teixidor, de México, tiene la tercera copia que conocemos.

Obras de consulta: Beristáin, Biblioteca ( $2^{3}$ edición, 1883), t. 2, p. 169; José Toribio Medina, Imprenta en México (Santiago de Chile, 1908-12), t. 8, núm. 11141, con el nombre del grabador equivocado.

Ejemplares: CtY, EM, JRS, TxU.

2. El Periquillo / Sarniento. / Por / El Pensador Mexicano. / Tomo I. / Segunda edición / coregida [sic] y aumentada por su autor. / México: 1825. / Oficina de don Mariano Ontiveros. / 
Tomo $1^{\circ}$ : portada, v. con el mismo epígrafe; p. [2] "Advertencia precisa"; [8] "Prólogo, dedicatoria y advertencias a los lectores"; [4] "Dedicatoria particular al exmo. Sr. Presidente de los Estados Unidos Mexicanos, ciudadano Guadalupe Victoria", fechada al fin a 2 de mayo de 1825; i-vi, "El prólogo de Periquillo Sarniento"; vii-x, "Advertencias generales a los lectores"; 1-286, texto en 12 capítulos como en la $1^{\text {a }}$ edición; [3] índice; [1] "Notas", atribuyendo la demora de la impresión a una epidemia y al grabador, que estaba ocupado con otros trabajos; [4] "Lista de los señores subscritores que hay hasta el día de hoy 19 de octubre de 1825, en que sale a luz este tomo primero", seguida de "Otra nota" (página final) dando el costo de la colección, 20 pesos.

$8^{\circ} 145 \times 100 \mathrm{~mm} .12$ grabados por Luis Montes de Oca, uno de los cuales es un retrato del Presidente de la República. La lista de suscritores contiene 78 nombres. Lizardi anunció el día 11 de enero de 1825, en El Sol, su intención de publicar esta edición; al día siguiente el mismo aviso salió en otro periódico, El Aguila Mexicana. González Obregón lo reimprimió en su biografía de Lizardi, p. 72-73. Dice el novelista que su obra aparecería corregida y aumentada en seis tomos. Al parecer no estaba en condiciones de cumplir lo prometido, porque sólo un tomo fué publicado. En la "Dedicatoria particular" revela Lizardi que el Presidente "ha protegido la [edición]. de esta obra, prestándome el papel necesario para la impresión del primer tomo". Tal vez sin la continuación de esta ayuda oficial le fuese imposible hallar los medios para seguir publicándola. Se omiten en esta edición las "Advertencias a los subscritores" de la primera; se agregan una "Advertencia precisa" y una "Dedicatoria particular". En la "Advertencia" reconoce el autor que los tiempos son otros y que ahora no se precisa de tanta disertación moral en la novela. Por lo tanto, dice, eliminó algunos párrafos y notas. En efecto, aquí echamos de menos 21 páginas y algunas notas del original. Tales omisiones hacen más fácil la lectura y también indican cómo cambió el autor sus opiniones y creencias desde 1816. Un pasaje eliminado trataba de la Virgen María como eficaz abogada; otro, de la inferioridad moral de la mujer. Las correcciones que promete el autor en la portada son en la mayor parte solaménte omisiones hechas del texto original, que son pocas pero de alguna extensión; las adiciones prometidas serían tal vez las aventuras de Periquillo contenidas en el tomo $4^{\circ}$, que no se imprimió con la primera edición.

Obras de consulta: Describimos por primera vez esta edición en "La desconocida segunda edición del 'Periquillo,", Revista de Literatura Mexicana, año I, núm. 2 (oct. / dic., 1940), p. 
[307]-317, con facsimiles de la portada, la $7^{3}$ hoja frente, la 1 página numerada y el primer grabado.

Ejemplar: C-S, único conocido, faltan las p. 45-48.

3. El / Periquillo Sarniento, / por / El Pensador Mexicano. / Tercera edición / corregida y aumentada por su autor. / [raya] / México: 1830. / Imprenta de Galván a cargo de Mariano Arévalo, / Calle de Cadena núm. 2. / [raya] / Se espende en la alacena de libros esquina al portal / de Mercaderes y Agustinos. /

Tomo 1: portada, v. con epígrafe; p. 3-4, "Advertencia"; 5-12, "Prólogo, dedicatoria y advertencia"; 13-18, "Prólogo de Periquillo Sarniento"; 19-22, "Advertencia general"; 23-258, texto en 13 capítulos; [2] índice.

Tomo 2:: portada, v.; p. 3-10, "Prólogo en trage de cuento"; 11-256, texto en 10 capítulos (II a XI del $2^{\circ}$ t., $1^{2}$ edición); [1] bl.; [2] indice.

Tomo $3^{\circ}:$ portada, v.; p. 3-262, texto en 10 capítulos (XII del $2^{\circ}$ t., I a $\mathrm{IX}$ del $3^{\circ}$ t., $1^{\mathrm{a}}$ edición); [2] índice.

Tomo $4^{\circ}$ : portada, v.; p. 3-209, texto en 10 capítulos ( $\mathrm{x}$ a Xn del $3^{\circ}$ t., la edición, más la parte manuscrita de la novela); [2] indice.

Tomo 5:: portada, v.; p. 3-172, texto en 9 capítulos; 173-175, "Voces provinciales que se encuentran en esta obra" ( 34 vocablos); [1] bl.; [2] índice; [1]. "Anuncio"; [1] bl.

$8^{\circ} 147 \times 95 \mathrm{~mm}$. 55 grabados sin firma, tal vez dibujados por Luis Montes de Oca. Las portadas de los tomos 2 a 5 son idénticas fuera del número del tomo y en el $5^{\circ}$ la fecha " 1831 " y "del Portal" en vez de "al Portal". En el t. 4, p. 73-74, precediendo al capítulo 4 , se hallan los documentos relativos a la censura del t. 4 de la $1^{3}$ edición, es decir, la carta de Lizardi fechada a 3 de octubre de 1816 pidiendo permiso para publicarlo, la carta oficial que manda censurarlo a Felipe Martínez. la crítica que hace éste de 19 de octubre, y por fin la respuesta negativa del Virrey, fechada a 29 de noviembre del mismo año. Estos documentos ya los poseía Lizardi para incluirlos en la $2^{3}$ edición. El "anuncio" en el t. 5 avisa que la novela está de venta "en la imprenta de estampas de la calle de las Escalerillas accesoria letra $A$, junto al núm. 11". Es de creerse, por lo 
tanto, que los grabados o "estampas" se hicieron en la misma imprenta. Las palabras "corregida y aumentada por su autor" dan a entender que el editor empleó el manuscrito preparado por Lizardi para la edición de 1825 . Comparando los 12 capítulos de la $3^{\mathrm{a}}$ edición que corresponden con la parte publicada de la $2^{a}$, se nota que hasta aquí por lo menos las dos ediciones se imprimieron del mismo manuscrito. Pero el resto de la $3^{3}$ edición casi nunca se aparta del texto de la $1^{3}$ edición. Por consiguiente llegamos a creer que Lizardi no llevó adelante la revisión iniciada, por no hallar modo de publicar más que un solo tomo de la $2^{\text {a }}$ edición. Además, tenía Lizardi la intención de dividir su novela en 6 tomos; el editor la publicó en 5 . En la última hoja del $2^{\circ}$ tomo de La Quijotita, publicada en 1831 , se nos informa que se vendía el Periquillo en 8 pesos la colección, sin encuadernar. Agrégase que "esta obra [el Periquillo] ha merecido tanto aprecio entre los mejicanos, que ha ecsedido al deseo de los editores".

Ejemplares: CLSU, CU-B, EM, MH, TxU.

4. El / Periquillo Sarniento, / por / El Pensador Mexicano. / [raya] / Cuarta edición / corregida, ilustrada con notas, y adornada / con sesenta láminas finas. / [orn.] Tomo r. [orn.] / México / [raya] / Se espende en la librería de Galván, / Portal de Agustinos número 3. / [raya]/.1842./

Tomo 1": portada, v. con epígrafe y "No se podrá reimprimir esta obra sin licencia del / propietario", esto es, Mariano Galván Rivera, y al pie de la página: "Imprenta de V. G. Torres, calle del Espíritu Santo N. 2."; p. [1] iv-xii, "L,igeros apuntes para la biografía del Pensador Mexicano"; xii-xxii, "Apología del Periquillo Sarniento, artículo inserto en los números 487 y 488 de 12 a 15 de febrero de 1819 del Noticioso General". [2] con otra portada:

E1 / Periquillo Sarniento, / por / El Pensador Mexicano. / Cuarta edición / corregida, ilustrada con notas, / y adornada / con sesenta láminas finas. / Tomo i [en viñeta]/ México: 1842. / [raya] / Se espende en la librería de Galván, / Portal de Agustinos núm. 3./

y la vuelta con el epígrafe, la prohibición de reimprimir y otro pie de imprenta: "Imprenta de J. M. Lara, calle de la Palma número 4"; [1] "Advertencia precisa"; [1] bl.; [1] vi-xi, "Prólogo, dedicatoria y advertencias a los lectores"; [1] bl.; p. [1] xiv-xvii, El prólogo de Periquillo Sarniento; [1] bl.; [1] xx, "Advertencias generales"; [1] 2-189, texto en 14 capítulos (capítulos $x$ a xir y I a II de la $1^{\text {a }}$ edición, tt. 1 y 2); [1] bl.; [2] índice. 
Tomo $2^{\circ}$ : portada, v. con epígrafe, declaración del editor y pie de imprenta: "Imprenta de V. G. Torres, calle del Espíritu Santo N. 2"; p. [1] iv-viii, "Prólogo en trage de cuento"; [1] 2-206, texto en 11 capítulos (III a XII y I de la $1^{\text {a }}$ edición, tt. 2 y 3 ); [2] indice.

Tomo $3^{\circ}$ : portada, v. igual al t. 2 ; p. [1] 4-196, texto en 11 capítulos (II a XII de la $1^{\text {a }}$ edición, t. 3); [2] índice.

Tomo $4^{\circ}$ : portada, v. igual al t. $2 ;$ p. [2] documentos relativos a la censura, como en la $3^{\text {a }}$ edición; [1] 6-225, texto en 16 capítulos; 226-230, "Pequeño vocabulario de las voces provinciales" (61 palabras, 7 variantes); [2] índice.

$8^{\circ} 174 \times 114 \mathrm{~mm}$. 15 litografías, sin firma, en cada tomo; retrato de Lizardi con facsímil de su firma en el frontispicio. Aquí se incluyen por primera vez la biografía anónima de Lizardi (¿por Mariano Galván Rivera?) y la "Apología" en la que el autor se defiende del ataque que le hizo Manuel Terán. Los preliminares fueron publicados en las ediciones anteriores. El editor pone una nota al fin de la "Advertencia precisa", explicando que ha agregado algunas notas para aclarar el sentido de ciertas palabras del texto. Una nota al pie de la página 139, tomo 4, declara que las correcciones hechas en tal edición vienen del "manuscrito que para esta edición se ha tenido a la vista, y de cuya autenticidad no se responde, aunque no faltan datos para creerlo del Pensador". Más tarde (p. 218), consta que le faltan al manuscrito las últimas seis páginas. Estudiando el texto descubrimos que se han cambiado algunas palabras, frases y notas que aclaran el significado de la obra. Pero es evidente que el manuscrito del editor no era el que se usaba para la impresión de la $2^{a}$ edición. A pesar de que se menciona la Imprenta de José Mariano Fernández de Lara en el primer tomo, no cabe duda de que la imprimió Vicente García Torres. Aquél solía hacer las litografías para ilustrar los impresos de García Torres, como lo demuestran las lindas ilustraciones del Semanario de las Señoñitas Mexicanas (1841-42), obra editada e impresa por García Torres. Luis González Obregón alguna vez (1938) dijo que esta edición es "sin disputa alguna . . . la mejor de las que se han hecho hasta ahora". En 1945 podemos afirmar lo mismo, aunque la biografía (excelente en aquel tiempo) ahora tiene poco valor.

Ejemplares: CtY, CLSU, CU-B, EM, MxCoah, MxF, MxFPR, NN, $\mathrm{TxU}$ : 
5. El Periquillo Sarniento, por El Pensador Mexicano. [raya] Quinta edición corregida, ilustrada con notas, y adornada con sesenta láminas. [orn.] Tomo I. [orn.] México: 1845. Se espende en la Librería número 7 del Portal de Mercaderes.

Juan B. Iguíniz, en su Bibliografia de novelistas mexicanos (México, 1926), p. 122, y Luis González Obregón (p. 68), nos dan esta descripción de una portada con que se vendieron los ejemplares que restaban de la edición anterior. Hasta hoy, no hemos podido encontrar en parte alguna un ejemplar con tal portada.

6. El / Periquillo Samiento, / por / El Pensador Mejicano. / Séptima edición / correjida e ilustrada con notas. / Tomo primero. / Santiago 1846. / Imprenta del Siglo. /

Tomo $1^{\circ}:$ p. [2] portada; i-xvi, hojas preliminares; [2] Advertencia precisa; 1-46, texto.

$4^{\circ} \mathrm{La}$ primera noticia de esta edición se halla en Estadística bibliográfica de la literatura cbilena (Santiago de Chile, 1862), t. I, p. 256. Allí el autor, Ramón Briseño, la describe así: "Periquillo Sarmiento [sic] (El), por el pensador mejicano. Prospecto", Santiago, Imprenta El Siglo, 1846,12 p., $4^{\circ}$ La misma nota aparece en otro libro del señor Briseño, su Catálogo de la Biblioteca Cbileno-Americana (Santiago, 1889), entrada número 7401. Don Raúl Silva Castro, el distinguido escritor chileno, en contestación a una carta que le dirigimos, tuvo la amabilidad de procurar y describir el ejemplar de la obra que se halla en la Biblioteca Nacional. Le debemos, por lo tanto, la descripción que ofrecemos y lo que sigue: " $\mathrm{El}$ prospecto no es otra cosa que una introducción del editor que revela el apellido del autor, a quien llama 'distinguido crítico y uno de los primeros talentos mejicanos', y que a continuación copia el prólogo del libro, se dirige al público para recomendar el libro y termina señalando las condiciones en que se iba a publicar la obra: entregas de 32 páginas cada una, sitios de suscripción, etc." En vista de eșto, debemos corregir la noticia que da Briseño. El texto de la edición de que nos ocupamos termina con esta frase: "Lo mismo, y no de mejor modo decía yo que sabía metafísica y" (corresponde a la página 53 de la $4^{\mathrm{a}}$ edición, t. I, al principio del capítulo 5). El señor Silva Castro añade que "me da la impresión de que el libro no se siguió publicando debido a que el público le encontraría carácter demasiado local para interesarse en él, a pesar de que el editor se había anticipado a esta observación haciendo un cumplidísimo elogio del autor y de su libro". No existe ra- 
zón alguna para llamar a esta edición "séptima"; como vemos, es la sexta. Tomó como modelo el texto de la edición de 1842 .

7. El / Periquillo Sarniento, / por / El Pensador Mexicano. / [raya] / Quinta edición, / corregida, ilustrada con notas, y adornada con / muchas láminas finas. / [raya] / Tomo 1. / México. / [raya] / Imprenta de M. Murguía y Comp., / Portal del Aguila de Oro. / [raya] / 1853./

Tomo 1": portada con epígrafe y "Esca obra es propiedad de D. Ignacio Altamirano. / La presente edición es propiedad de D. M. Murguía y Co"; p. [1] 4-272, texto en 14 capitulos; [2] índice.

Tomo $2^{\circ}$ : portada, v. ídem t. I; p. [1] 4-285, texto en 11 capitulos; [1] bl.; [2] indice.

Tomo $3^{\circ}:$ portada, v. ídem t. I; p. [1] 4-285, texto en 11 capítulos; [1] bl.; [2] índice.

Tomo 4\%: portada, v. ídem t. $\mathrm{x}$; p. [1] 4-321, texto en 16 capítulos; 322-329, "Pequeño vocabulario"; [1] bl.; [3] índice; [1] bl.

$8^{\circ} 140 \times 87 \mathrm{~mm}$. Litografías copiadas de la edición de 1842, 15 (?) en cada tomo. Toma como modelo el texto de la edición de 1842 , omitiendo, sin embargo, todas las hojas preliminares y los documentos relativos a la censura.

Ejemplares: EM, MH.

8. El / Periquillo Sarniento, / por / El Pensador Mexicano. / [raya] / Primera edición de Blanquel, / Corregida, ilustrada con notas, y adornada / con 56 láminas finas. / [raya] / Tomo I. / [raya] / México. / [raya] / Se espende en la librería de Blanquel, / calle del Teatro Principal número 13. / [raya $] / 1865$. /

Tomo 1": portada, v. con epígrafe y "Esta obra es propiedad de Simón Blanquel, y nadie / la podrá reimprimir sin su permiso. / Imprenta de Luis Inclán, cerca de Sto. Domingo $N^{\circ} 12 " ;$ p. [1] iv-xxi, biografía de Lizardi y la Apología; [1] bl.; [1] 6-12, "Prólogo, dedicatoria y advertencia a los lectores"; [1] 14-17, "Prólogo de Periquillo Sarniento"; [1] bl.; [1] 20, "Advertencias generales"; [1] 22-215, texto en 14 capítulos; [1] bl.; [2] índice.

Tomo $2^{\circ}$ : portada con estos cambios: línea 3 "por el", línea 5 omite "de Blanquel", línea 9 "México: 1865/Se espende"..., 
y se omite la última línea; v. de la portada ídem t. 1; p. [1] 4-8, prólogo; [1] 10-220, texto en 11 capítulos; [2] índice.

Tomo $3^{\circ}$ : portada como en el t. 2 ; p. [1] 4-206, texto en $11 \mathrm{ca}$ pítulos; [2] indice.

Tomo $4^{\circ}$ : portada como en el t. 2 ; [1] 4, los documentos referentes a la censura; [1] 6-237, texto en 16 capítulos; 238-244, "Pequeño vocabulario"; [2] índice; [2] "Pauta para la colocación de las láminas".

$8^{\circ} 160 \times 118 \mathrm{~mm} .15$ litografias, sin firma, en $\operatorname{los} \mathrm{tt} .1,2$ y 3 ; 10 en el t. 4. Copia el texto de la edición de 1842 .

Ejemplares: CU-B, DLC, EM, MH.

9. E1 / Periquillo Sarniento / por / El Pensador Mexicano / [raya] / Edición de "El Diario del Hogar." / [raya] / Tomo I. / [raya] / México / Tipografía literaria de Filomeno Mata / Betlemitas 8 y 9./ 1844. /

Tomo 1\%: portada, v. bl.; p. [1] iv-xxv, biografía de Lizardi y'la Apología; [1] bl.; [2] otra portada igual a la primera, v. con epígrafe; [2] "Advertencia precisa", v. bl.; [1] 6-12, prólogo, etc.; [1] 14-17, "E1 prólogo de Periquillo Sarniento"; [1] bl.; 19-21, "Advertencias generales"; [1] bl.; [1] 24-271, texto en 14 capítulos; [1] bl.; 273-275, índice; [3] bl.

Tomo $2^{\circ}:$ portada con el cambio del año a 1885 , v. bl.; [2] cpígrafe v. bl.; [1] 6-11, "Prólogo en trage de cuento"; [1] bl.; [1] 14-281, texto con prólogo y 11 capítulos; [1] bl.; [1] 2-3, indice; [1] bl.

Tomo $3^{\circ}$ : portada como en el t. 2, v. bl.; [2] epígrafe, v. bl.; [1] 6-258, texto en 11 capítulos; [1] bl.; 260-261, índice.

Tomo 4": portada, con la fecha "1885", v. epígrafe; p. [1] 4-5, "Manuscrito que el autor dejó"; [1] bl.; [1] 8-290, texto en 16 capitulos; 291-298, "Pequeño vocabulario"; 299-302, indice.

$8^{\circ} 155$ x $100 \mathrm{~mm}$. Copia la edición de 1842.

Ejemplar: $\mathrm{MxF}$. 
10. El / Periquillo Sarniento / por / El Pensador Mexicano / [raya] / Segunda edición / corregida, ilustrada con notas, y adornada con $30 /$ láminas finas. / [raya]/Tomo I. / [raya]/ México. / [en una columna a la izquierda:] J. Valdés y Cueva, / Calle del Refugio núm. 12. / [a la derecha:] R. Araujo, / Calle de Cadena, número 13. / 1884. /

Tomo 1": portada, v. con epígrafe y al pie de la página: "Tip. Clarke y Macías. Tiburcio n. 2"; p. [1] 4-183, texto en 14 capítulos; [1] bl.; [2] índice.

Tomo $2^{\circ}$ : portada, fecha " $1885^{\circ}$, v. con epígrafe y "Tip. de Clarke y Macías, Arco de San Agustín, 19"; p. [1] 4-7, prólogo; [1] 9-211, texto en 11 capítulos; [1] 213 , indice; [1] bl.

Tomo 3:: portada como en el t. 2; p. [1] 4-204, texto en 11 capítulos; [2] índice.

Tomo 4?: portada como en el t. 2, v, con el epígrafe y "El Gran Libro. Independencia, 9"; [1] 4, documentos de la censura; [1] 6238, texto en 16 capítulos; [1] 240-245, "Pequeño vocabulario";

[1] bl.; [1] ii-iii, índice; [1] bl.

$4^{\circ} 183 \times 135 \mathrm{~mm} .30$ litografías grandes, algunas firmadas con las iniciales "L G", esto es, L. Garcés, competente litógrafo. Sus ilustraciones son más imaginativas que las de sus predecesores. No se incluyen los preliminares de la novela. Texto tomado de la edición de 1842 .

Ejemplares: $\mathrm{EM}, \mathrm{MH}, \mathrm{MxF}, \mathrm{MxJ}, \mathrm{NcD}$.

11. A. Paz y A. Silva y Valencia, editores. / El / Periquillo Sarniento / por / D. José Joaquín Fernández de Lizardi / (El Pensador Mexicano) / Nueva edición adornada con multitud de cromos / y fotograbados / por Don José M. Villasana y precedida de un estudio biográfico / y bibliográfico / Por Don Luis González Obregón / (Del Liceo Mexicano) / Tomo r. / México. / Imprenta, Litografía y Encuadernación de Ireneo Paz. / Segunda del Relox 4, calle Norte 7 número 127. / 1892./

Tomo $1^{\circ}:$ p. $[4], 1-36$.

Folio. Quedó trunca. Tomamos la descripción de la bibliografía de González Obregón, p. 70. Véase también Juan B. Iguíniz, Bibliografía de novelistas mexicanos (México, 1926), p. 123.

Ejemplar: MxFLGO. 
12. El / Periquillo Sarniento / por / el Pensador Mexicano / [raya] / [orn.] / Novísima edición. [orn.] / [raya] / Tomo I. / [raya] / Méxíco. "La Ilustración de México" / calle del Correo Mayor núm. 410. / [raya]/1896. /

Tomo $1^{\circ}$ : portada, v. bl.; p. [1] 4-185, texto que comienza con el primer capítulo de la novela.

Tomo $2^{\circ}:$ no vimos este tomo.

Tomo 3: p. 1-192.

Tomo 4: p. 1-226; iii.

$4^{\circ} 160 \times 110 \mathrm{~mm}$. Poseemos sólo el t. I; vimos el $3^{\circ}$ y $4^{\circ}$ en una librería mexicana, hace años. Edición de folletín que no conocían Spell y González Obregón. La portada del t. 3 es diferente: "El Periquillo Sarniento por el Pensador Mexicano. Novísima edición corregida, ilustrada con notas y adornada con 50 láminas finas. Tomo nrr. México, 'La Ilustración de México', 1896." Los errores tipográficos abundan. La fecha, "1896", se repite en el t. 4. El t. 1 no tiene ilustraciones. Edición pésima.

13. El Pensador Mexicano / (J. Joaquín Fernández de Lizardi) / [raya / E1 / Periquillo Sarniento / La Quijotita / Don Catrín de la Fachenda.-Noches tristes / Día alegre.-Fábulas / Prólogo de / D. Francisco Sosa / [raya] / Edición de lujo / adornada con láminas cromolitografiadas, y enriquecidas sus páginas / con numerosos grabados / dibujos de / D. Antonio Utrillo / [raya] / Tomo I / [raya] / México / J. Ballescá y Compañía, Sucesor / 8, Santa Isabel, 8/ [raya] / Santa Teresa, 8, Barcelona-Gracia / 1897. /

Tomo $1^{\circ}$ : anterportada, v, con propiedad literaria; portada v. epígrafe, título a negro y rojo; p. [1] ii-viii, prólogo firmado por Francisco Sosa en 1896; [1] 2-289, texto en 14 capitulos; [1] bl.; [2] portada del índice, v. bl.; [1] 294, indice; [2] pauta de las ilustraciones, v. con colofón: "Este tomo se / acabó de imprimir en Barcelona, / en el establecimiento tipo-litográfico / de Espasa y Compañía, / en agosto de / 1897."”

Tomo $2^{\circ}$ : anteportada como en el t. I; portada como en el t. 1 , pero con el cambio "tomo I / B /", v. bl.; p [1] 2-305, texto en 11 capítulos; [1] bl.; [2] portada del índice, v. bl.; [1] 310 , índice; [2] pauta de las ilustraciones, v. con colofón igual al t. 1. 
Tomo 3:' anteportada como en el t. 1; portada igual al t. 1, pero con el cambio. "Tomo II / C / ", v. bl.; v. [1] 2-291, tex́to en 11 capítulos; [1] bl.; 2 portada del índice, v. bl.; [1] 296, índice; [2] pauta de las ilustraciones, v. con colofón que dice que se publicó en el mes de septiembre; [2] bl.

Tomo 4\%: anteportada igual al t. 1 ; portada como en el t. 1, pero "Tomo II / D /", v. bl.; p. [1] 2-337, texto en 16 capítulos; [1] bl.; [1] 340-344; "Pequeño vocabulario"; [2] portada del índice, v. bl.; [1] 348-349, indice; [1] bl.; [2] pauta de las ilustraciones, v. con colofón (se publicó en octubre).

Folio, $275 \mathrm{~mm}$. Los tt. 1 y 4 tienen cada uno 4 láminas en colores; los otros tienen 3; frontispicio con retrato de Lizardi (de la edición de 1842): Numerosas litografías en el texto. Fuera de la parte preliminar, esta edición copia el texto de la de 1842. Sin embargo, hay unos cambios en lás notas y en el vocabulario. A pesar de que el editor promete publicar todas las obras mayores de Lizardi, sólo dió a luz ésta y La Quijotita.

Ejemplares: 'CLSU, DLC, IU, MxF, MxFL, MxFU.

14. Biblioteca económica, lectura amena e instructiva. / Editor, José Barbier. / El Periquillo Sarniento / por / El Pensador Mexicano / Tomo r. / México, Oficinas de El Universo. / 1900. /

Tomo $1^{\circ}:$ p. $1-14$.

$16^{\circ}$ Tomamos esta descripción de Juan B. Iguíniz y Luis González Obregón. Al parecer, sólo se publicó la primera entrega.

Obras de consulta: González Obregón, p. 71; Iguíniz, obra citada, p. 124.

15. El / Periquillo Sarniento / por / El Pensador Mexicano / edición corregida, / ilustrada con notas y adornada con / veinticuatro láminas / [raya] / Tomo I / [raya] / Casa editorial de / [en una columna a la izquierda:] Maucci Hermanos é Hijos / Buenos Aires / [a la derecha:] Maucci Hermanos / México / [abajo:] José López Rodríguez / Habana. /

Tomo 1": anteportada, v. bl.; portada, v.: "Tip. Casa Editorial Sopena, Valencia, 363, Barcelona"; p. [2] Advertencia precisa, v. bl.; [1] 8-9, prólogo fechado noviembre de 1901 y firmado por Luis González Obregón; [1] bl.; [1] 12-32, biografía de Lizardi y su Apología; [1] 34-40, "Prólogo, dedicatoria", etc.; [1] 
42-43, Advertencias generales; [1] epígrafe de Torres Villarroel; [1] 46-48, Prólogo de Periquillo Sarniento; [1] 50-527, texto en 24 capítulos; [1] bl.

Tomo $2^{\circ}$ : anteportada, v. bl.; portada, v. como en el t. 1 ; p. [1] 6, documentos de la censura; [1] 8-12, Prólogo en traje de cuento; [1] 14-519, texto en 27 capítulos; [1] bl.; [1] 522-527, Pequeño vocabulario; [1] bl.

$16^{\circ} 177 \times 105 \mathrm{~mm}$. Reproduce en fotolitografias las láminas de la edición de 1842 , a la que sigue cuidadosamente en el texto. Valiosa por ser exacta en la impresión y por contener el prólogo de González Obregón, gran lizardista. En otra parte, éste deja escrito que fué publicado en 1903.

Obra de consulta: González Obregón, p. 71-72.

Ejemplares: $\mathrm{MB}, \mathrm{MxF}, \mathrm{NNC}, \mathrm{TxU}$.

16. Biblioteca de Grandes Novelas / [raya] / El Periquillo Sarniento / por / El Pensador Mexicano / [raya] / Edición corregida é ilustrada / [sello de imprenta] / Barcelona / Casa Editorial Sopena / Provenza, $95 / 1908 . /$

Tomo 1': anteportada, v. bl.; portada, v.: "Imp. y estereotipia de la Casa Editorial Sopena, Provenza, 95. Barcelona"; p. [1] 2, prólogo de un escritor anónimo; [1] 4-9, biografía de Lizardi y la Apología; [1] bl.; [1] 12-13, Prólogo, dedicatoria, etc.; [1] bl.; [1] Advertencias generales; [1] epígrafe; [1] 18, Prólogo de Periquillo Sarniento; [1] 20-154, texto en 24 capitulos; [2] título "Segunda Parte" y los documentos de la censura, v. bl.; [1] 158, Prólogo en traje de cuento; [1] 160-303, texto en 27 capítulos; [1] bl.; [1] 306-307, Pequeño vocabulario; [1] bl.; [1] 310-311, indice; [1] bl.

$8^{\circ} 230 \times 155 \mathrm{~mm}$. 5 láminas firmadas por $\mathrm{V}$. Buil e impresas en tinta azul. Texto (a dos columnas) del tipo de 1842, con capítulos dispuestos como en la edición anterior.

Ejemplares: CSt, CU-B, CtY, TxU.

17. Biblioteca de Grandes Novelas / El Periquillo Sarniento / por / El Pensador Mexicano / [raya] / Versión castellana / [sello de imprenta] / Buenos Aires / Casa editora "La Nación" / 1910./ 
Tomo 1": portada, v.: "Imp. y estereotipia de la casa editorial Sopena, Provenza, 95. Barcelona"; p. [1] 2, Prólogo; 3-9, Ligeros apuntes; 11-13, Prólogo, dedicatoria, etc.; 15, Advertencias generales; 16, epígrafe; 17-18, Prólogo de Periquillo Sarniento; 19-296, texto; 297-303, Notas del Pensador; $305-307$, Pequeño vocabulario; 309-311, índice.

Ricardo Victorica, que suministra el título y la fecha de esta edición en Errores y omisiones del Diccionario de anónimos $y$. pseudónimos bispanoamericanos de José Toribio Medina (Buenos Aires, 1928), p. 126, deja entender que fué impresa en la Argentina, pero la descripción completa demuestra que no era así. El señor Antonio Aita, de la Comisión Nacional de Cooperación Intelectual de la Argentina, y el docto señor Angel Rosenblat, del Instituto de Filologia (Buenos Aires), amablemente procuraron a nuestro pedido un ejemplar de esta edición. A juzgar por los datos que nos transmitió el señor Rosenblat, se hizo la impresión con los estereotipos de la edición de 1908, añadiendo una portada nueva.

18. Biblioteca de Grandes Novelas / El Pensador Mexicano / [raya] / El Periquillo Sarniento / [escudo de imprenta] / Editorial Sopena, S. A. / Provenza, 95 / Barcelona / 1933./

Tomo 1": portada, v.: "Gráficas Ramón Sopena, S. A. Provenza, 97, Barcelona"; p. [1] 2, Prólogo del editor; [1] 4-9, biografía de Lizardi y su Apología; [3] Prólogo, dedicatoria, etc.; [1] Advertencias generales; [1] epígrafe; [1] 18, Prólogo de Periquillo Sarniento; [1] 20-154, texto en 24 capítulos; [1] título de la "Segunda parte" y los documentos de la censura; [1] bl.; [1] 158, Prólogo en traje de cuento; [1] 160-303, texto en 27 capítulos; [1] bl.; [1] 306-307, Pequeño vocabulario; [1] bl.; [1] 310-311, índice; [1] bl.

$8^{\circ} 230 \times 155 \mathrm{~mm}$. Impreso con los estereotipos de la edición de 1908. Algunos de los títulos a la cabeza de las páginas, así como los de las secciones, fueron refundidos. Se omitieron las ilustraciones y varias páginas blancas de aquella edición. Nueva portada.

Ejemplares: DLC, EM, ViU.

19. Biblioteca de Grandes Novelas / [raya] / El Pensador Mexicano / [raya] / El Periquillo Sarniento / [escudo de imprenta] / Barcelona / Ramón Sopena, Editor / Provenza, 93 a 97. / 
Tomo 1": portada, v.: "Ramón Sopena, impresor y editor, Provenza, 93 a 97. Barcelana"; lo demás, como en la edición de 1933.

$8^{\circ} 230 \times 155 \mathrm{~mm}$. Fuera de algunos cambios de títulos, como la edición anterior es idéntica a la impresión de 1908. Por ser la impresión menos clara que la de 1933, la juzgamos de una fecha posterior.

Ejemplares: $\mathrm{MdBJ}$, OO, RPB.

20. José Joaquín / Fernández de Lizardi / [raya] / El Periquillo / Sarniento / selections by / María López de Lowther / University of California at Los Angeles / Part I / New York / Oxford University Press / 1937./

Tomo $1^{\circ}$ : portada, v. propiedad literaria; p. [1] 4, Nota de Aurelio M. Espinosa; [1] 6-32, texto en 11 capítulos; [1] 34-48, vocabulario español-inglés.

Tomo 2": portada con "Part II" y "1939"; v. como en el t. 1; p. [1] 4, Nota idéntica; [1] 6-41, texto en 11 capitulos; [1] bl.; [1] 44-68, vocabulario español-inglés.

$168 \times 155 \mathrm{~mm}$. Libro de texto para estudiantes de la lengua española. El prólogo describe los propósitos de la serie de libros de la cual forma parte. Una breve noticia biográfica precede al texto, que consiste en selecciones tomadas de la novela y simplificadas. A cada capítulo sigue una lista de modismos y varias preguntas. En el forro del t. 1: "Oxford Rapid-Reading Spanish Texts / Based on Word-Frequency / General Editor: Aurelio M. Espinosa / Grade I"; el t. 2 omite la segunda línea y lleva el "Grade III".

Ejemplares: DLC, EM.

21. José Joaquín / Fernández de Lizardi / [raya] / El Periquillo / Sarniento / selections by / María López de Lowther / University of California at Los Angeles / Part x / New York / Oxford University Press / 1939. /

Tomo 1:: portada, v. con propiedad literaria de 1937 y 1939 ,

"New edition, revised and corrected, 1939"; p. [1] 4, Nota; [1]

6-32, texto en 11 capitulos; [1] 34-49, vocabúlario español-inglés; [3] bl.

$168 \times 115 \mathrm{~mm}$. Parece que se hizo con los estereotipos de la edición de 1937 en la parte que toca al texto; cambios de poca importancia en las otras partes.

Ejemplares: DLC, EM. 
22. [entre orla al pie de la página:] E1 / Periquillo Sarniento / por / El Pensador Mexicano / Tomo I / Publicaciones Herrerías, S. A. / Bucareli 23, México, D. F. /

Tomo 1\%: portada, v. bl.; p. [1] 4-46, texto en 14 capítulos.

Tomo $2^{\circ}:$ portada ídem, v. ídem; p. [1] 4-51, prólogo y texto en 11 capítulos; [1] bl.

Tomo $3^{\circ}$ : portada 1 dem, v. ídem; p. [1] 4-48, texto en 11 capítulos.

Tomo 4: portada ídem, v. ídem; p. [1] 4-53, documentos de la censura y texto en 16 capítulos; [1] bl.; 55-56, Pequeño vocabulario.

$4^{\circ} 284 \times 195 \mathrm{~mm}$. Reproduce en el texto las litografías de la edición de Valdés y Cueva (1884). Texto a dos columnas. Publicada probablemente en los primeros meses de 1939. Pésima edición en cuanto a la tipografía y al papel, que rivalizan con las de 1896.

Ejemplar: EM.

23. E1 Periquillo Sarniento / Por / José Joaquín Fernández de Lizardi / Prefacio / de / Octavio N. Bustamante / Grabados en madera / de / Julio Prieto / Litografías de la edición de 1842 / [raya doble] Editorial Stylo / México, 1942. /

Tomo $1^{\circ}:$ p. [2] bl.; [1] anteportada; [1] al pie: "Talleres de la Editorial Stylo. / Caso, Bustamante y Cía., S. de R. L. / Mérida 204, México, D. F."; [1] título "Primera parte" y grabado; [1] bl.; [2] portada, v. bl.; [2] prefacio de Octavio N. Bustamante, título, v. bl.; xi-xix, prefacio del mismo; [1] bl.; [2] título del Prólogo, dedicatoria, etc., v. bl.; 3-9, prólogo; [1] bl.; [2] advertencias generales, título, v. bl.; 13-14, Advertencias; [2] título del Prólogo de Periquillo Sarniento, v. bl.; 17-20, Prólogo; [4] 25475 , texto en 25 capítulos; [1] bl.; [2] título del índice, v. bl.; 479-482, indice; [2] bl.

Tomo $2^{\circ}:$ [2] bl.; [2] portada:

José Joaquín Fernández de Lizardi / El Periquillo / Sarniento / Segunda parte / [grabado en madera] / Editorial Stylo / México, D. F. / 
v. bl.; [2] título, v. bl.; 7-8, documentos de la censura; [2] título, v. bl.; 11-15, Prólogo en traje de cuento; [1] bl.; [4] 21-500, texto en 27 capítulos; [2] título, v. bl.; 503-506, índice; [2] bl.; [2] colofón: "En enero de 1942, la Editorial Stylo, / Caso, Bustamante y Cía., S. de R. L., / tiró 3,000 ejemplares de 'El Periquillo / Sarniento' en papel 'Marfileño'; 20 / ejemplares en papel 'Corsican Dekl' Text' / numerados de 1 al 20; y 10 ejemplares / numerados del $\mathrm{x}$ al $\mathrm{x}$, en el mismo papel / fuera de comercio. / Satylo. /, v. bl,; [2] bl.

$8^{\circ} 200 \times 150 \mathrm{~mm} .8$ ilustraciones en cada tomo copiando las litografías de la edición de 1842 . Bustamante revela en el prefacio que se sirvió también del texto de aquella edición. Los pasajes en los cuales Lizardi interrumpe la historia y moraliza son impresos en bastardilla para que el lector los evite o los procure, según sus predilecciones. No se incluyen la biografía, la apología y las notas del editor de aquella edición.

24. The Itching / Parrot El Periquillo / Sarniento By José Joaquín Fernández de / Lizardi (The Mexican Thinker) Translated from / the Spanish, and with an Introduction by / Katherine Anne Porter / [orn.] / Garden City, New York / Doubleday, Doran and Co., Inc. 1942. /

Tomo 1": p. [2] anteportada, v. bl.; [2] portada, v.: "Printed at the Country Life Press, Garden City, N. Y., U. S. A. / and copyright by publisher"; [2] epígrafe, v. bl.; vii-viii, Acknowledgments, firmado por la señorita Porter; ix-xii, índice; xiii-xiiii, Introduction de la misma, 10 diciembre 1941; [1] bl.; [2] título, v. bl.; [1] 2-290, texto en 33 capítulos y un epílogo.

$8^{\circ} 208 \times 137 \mathrm{~mm}$. Revela en los Acknowledgments que Eugene Pressly hizo la traducción, que Donald Elder seleccionó el texto y que Katherine Anne Porter lo revisó y editó. Se han omitido muchos pasajes moralizadores y se redujo el texto a casi la mitad del original. La traducción no desmerece la obra; la introducción, a pesar de algunos errores, es la mejor que tenemos en las ediciones del Periquillo. Es la primera traducción a otra lengua de esta novela.

Ernest Richard Moore, Oberlin College. 


\section{$\mathrm{N} O \mathrm{~T} A \mathrm{~S}$}

Nos place reconocer y agradecer la colaboración de nuestros colegas don Rafael Carrasco Puente, el doctor Roberto Valles y el doctor Ralph Warner, que leyeron esta bibliografía en manuscrito.

1 Véase nuestro número 24 , adelante.

2 Idem., p. xxxvi.

3 Luis González Obregón, Don José Joaquín Fetnández de Lizardi (Et Pensador Mexicano), México, Ediciones Botas, 1938, pp. [67]-72. Debe consultarse también Jefferson R. Spell, The Life and Works of José Joaquín Fernández de Lizardi, Philadelphia, 1931, $141 \mathrm{pp}$. Frecuentemente nos referimos a ambas bibliografías en este catálogo.

4 La señorita Porter, en la introducción del Itching Partot, p. xxxv, dice erróneamente que ya había ocho ediciones en el año 1884 (eran diez); Enrique Fernández Ledesma, Historia crítica de la tipogtafia en la ciudad de México, México, 1935 , p. 42, da por todo diez (había dieciocho); Octavio N. Bustamante, editor de la última edición mexicana (número 23, abajo), sigue a Fernández Ledesma y comete el mismo error. 



\section{N F O R M A I O N}

En el año de 1945 varios países de América conmemoraron fechas de nacimientos o defunciones de grandes personalidades -en las letras, en las ciencias o en las artes- de las naciones que ilustraron con su obra. Así, México recordó los doscientos cincuenta años que nos separan de la muerte de Sor Juana Inés de la Cruz y los tres siglos transcurridos del nacimiento de don Carlos de Sigutienza y Góngora, el ilustre contemporáneo y amigo de la monja.

Cuba recordó la infausta fecha de la muerte de Martí, en su cincuentenario. El Brasil celebró el centenario del nacimiento del Barón de Rio Branco, y con relación al tema hemos recibido un artículo debido a la docta pluma de Phocion Serpa.

En la imposibilidad de publicarlo íntegro, y como un homenaje al estadista brasileño y a la patria que él sirvió con tanto decoro, publicamos a continuación tuno de los capítulos de la biografía que su compatriota Serpa le dedica. 
